\title{
EVOLUÇÃO DA AVALIAÇÃO DE DESEMPENHO DE FORNECEDORES - FERRAMENTA GERENCIAL EM UNIDADES DE ALIMENTAÇÃO E NUTRIÇÃO.
}

\section{Fátima A. Castanheira, Vilma L. Ribeiro, Cristina T. Kariya, Rosiris Alonso}

\section{Introdução}

Os fornecedores devem ser vistos como parte na gestão da cadeia de produção de refeições, sendo submetidos a avaliação contínua de desempenho e estimulados a rever constantemente seus processos. Assim, avaliar o desempenho de fornecedores é um investimento no desenvolvimento de parceiros que atendam às exigências legais e das unidades (BASILIO; MARTINS; SILVA 2014).

Esta avaliação é realizada através da utilização de indicadores e critérios que devem estar inseridos nas atividades de rotina da instituição e dos fornecedores, pois definem diretrizes a serem adotadas, com o objetivo de aprimorar a qualidade dos produtos e processos (CASTANHEIRA 2015).

O nível de serviço prestado pelos fornecedores pode ser mensurado por indicadores de desempenho como a porcentagem de entregas realizadas dentro do prazo, tempo de entrega, recebimento do pedido de acordo com as especificações ou a porcentagem de entregas devolvidas parcial ou integralmente. Um excelente desempenho no serviço oferecido aos clientes aumenta de modo substancial o valor agregado em toda cadeia de suprimentos (CONCEIÇÃO; QUINTÃO 2014).

Mediante o exposto, as unidades de nutrição de uma instituição pública na área da saúde que realizam um trabalho de avaliação de desempenho de fornecedores conseguem verificar a evolução dos resultados, utilizando as ferramentas de gestão da qualidade.

\section{Objetivo}

Apresentar a evolução dos resultados da avaliação de desempenho de fornecedores com as intervenções realizadas.

\section{Método}

Nas unidades de nutrição de um Complexo Hospitalar Público, cuja aquisição de insumos é realizada por processo licitatório, temse média anual de 54 fornecedores. A avaliação de desempenho entre 2014 e 2017 foi baseada nos seguintes critérios e etapas:

- Recebimento da matéria prima usando indicadores referentes aos prazos e condições de entrega;

- Avaliação do produto no período de armazenamento;

Registro das não conformidades;

Ações corretivas adotadas pelos fornecedores;

- Participação nos encontros de fornecedores promovidos pela instituição e os resultados obtidos nas visitas técnicas.

Estas etapas receberam pontuação que permitiram a classificação em três níveis: Satisfatório, Parcialmente Satisfatório e Insatisfatório. Porém, para a adoção de planos de ação, consideram-se as 02 últimas classificações.

Mensalmente, os fornecedores que não atingem as metas recebem feedback de desempenho parcial e, após a tabulação anual, todos são informados dos resultados obtidos, sendo solicitados planos de ação com prazos de implementação.

Visando melhorias nos processos e nas avaliações para os fornecedores classificados como parcialmente satisfatórios/insatisfatórios foram adotadas as seguintes medidas: capacitação de ações corretivas e preventivas; atualização do Manual do Fornecedor elaborado pelas unidades das nutrições com ênfase nas normas para as não conformidades observadas, aplicação de questionário sobre os critérios de fornecimento à Instituição e conscientização com utilização de formas lúdicas.

\section{Resultados}

$\mathrm{Na}$ avaliação de desempenho em 2014 a 2017, os fornecedores classificados como satisfatórios representaram respectivamente $27 \%, 48 \%, 54 \%$ e $57 \%$ do universo total e como parcialmente satisfatórios/insatisfatórios $73 \%, 52 \%, 46 \%$ e $43 \%$.

Gráfico 1. Classificação da Avaliação de Desempenho de Fornecedores - 2014 a 2017

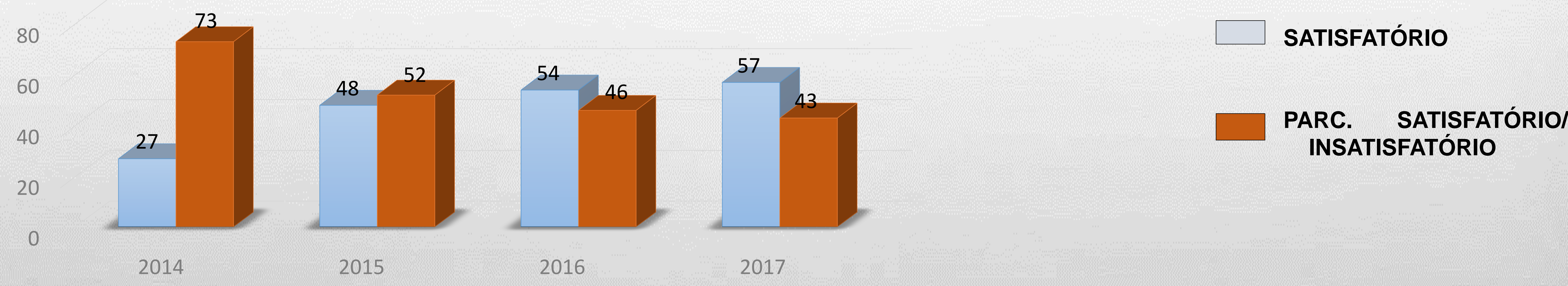

\section{Conclusão}

Os resultados demonstraram que, ao longo dos anos, houve uma evolução no percentual de fornecedores classificados como satisfatórios, o que indica que os planos de ações apresentaram eficácia. 